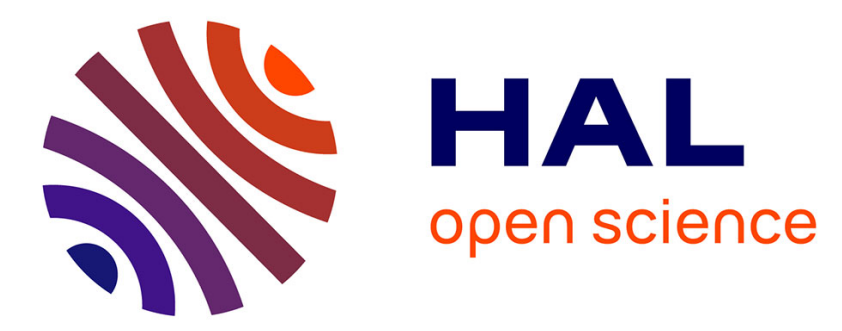

\title{
Dual-Multiphase Motor Drives for Fault- Tolerant Applications: Power Electronic Structures and Control Strategies
}

Tiago Jose dos Santos Moraes, Ngac Ky Nguyen, Eric Semail, Fabien Meinguet, Mael Guerin

\section{To cite this version:}

Tiago Jose dos Santos Moraes, Ngac Ky Nguyen, Eric Semail, Fabien Meinguet, Mael Guerin. DualMultiphase Motor Drives for Fault- Tolerant Applications: Power Electronic Structures and Control Strategies. IEEE Transactions on Power Electronics, 2017, pp.1-1. 10.1109/TPEL.2017.2671907 . hal-01529658

\section{HAL Id: hal-01529658 \\ https://hal.science/hal-01529658}

Submitted on 31 May 2017

HAL is a multi-disciplinary open access archive for the deposit and dissemination of scientific research documents, whether they are published or not. The documents may come from teaching and research institutions in France or abroad, or from public or private research centers.
L'archive ouverte pluridisciplinaire HAL, est destinée au dépôt et à la diffusion de documents scientifiques de niveau recherche, publiés ou non, émanant des établissements d'enseignement et de recherche français ou étrangers, des laboratoires publics ou privés. 


\title{
Dual-Multiphase Motor Drives for Fault- Tolerant Applications: Power Electronic Structures and Control Strategies
}

\author{
Tiago José dos Santos Moraes ${ }^{1}$, Ngac Ky Nguyen ${ }^{1}$, Member, IEEE, Eric Semail ${ }^{1}$, Member, IEEE, Fabien Meinguet ${ }^{2}$, \\ Mael Guerin ${ }^{3}$, \\ ${ }^{1}$ Univ. Lille, Centrale Lille, Arts et Métiers ParisTech, HEI, HeSam, EA 2697 - \\ L2EP - Laboratoire d'Electrotechnique et d'Electronique de Puissance, F-59000 Lille, France \\ ${ }^{2}$ Thales Alenia Space, Charleroi, Belgium \\ ${ }^{3}$ Thales Avionics Electronics System, Chatou, France \\ E-mail : ${ }^{1}$ tiago.dossantosmoraes; ngacky.nguyen; eric.semail $\} @$ ensam.eu \\ ${ }^{2}$ fabien.meinguet@thalesaleniaspace.com \\ ${ }^{3}$ mael.guerin@fr.thalesgroup.com
}

\begin{abstract}
This paper analyzes two fault-tolerant dualmultiphase motor drives, a series connected topology and a standard H-bridge topology. Previous studies have shown that the series connected topology is appropriate to an aerospace application and has lower peak current in degraded mode in comparison with the H-bridge topology, which may consequently diminish the system's weight and cost. This paper extends the study to compare different control strategies of these structures under two fault conditions: short-circuit of an inverter's switch and an open-phase of the machine. The control strategies analyzed in this paper do not impact the fundamental current or the torque generation, but the amplitudes of some harmonics in degraded mode are expected to be narrowed down in order to reduce the inverter's size. Some analyses of maximum voltage and peak current in degraded mode have been used for inverter dimensioning. Experimental results are shown and compared to the simulated ones to confirm the validity of this study.
\end{abstract}

Keywords - series connected; multiphase dual-motor; faulttolerant; control strategy; short-circuit fault.

\section{INTRODUCTION}

Different types of energy are present in aircrafts and space rockets. Chemical energy is mainly used in the propulsion while mechanical, pneumatic, hydraulic and electrical energies are used in all other applications as flight control, landing gear and Wing Ice Protection Systems (WIPS). Each type of energy has its own advantages in comparison with the others. But recently, the electrical applications have been replacing other standard systems because of their reliability and flexibility [1][5].

In both aerospace and aeronautic industries, the most important constraints are similar: weight, reliability and cost. A light system reduces the fuel consumption, because the system's weight has to be lifted and maintained in the air. The power densities of electric machines, semi-conductors components and batteries have been increasing thanks to the technological advance. Mutualizing electrical sources and/or inverter legs may also reduce the system's weight. Some studies have presented different innovative topologies leading to weight reduction without compromising its performance as series and parallel machines connection [6]-[10]. Both industries have high standards of reliability in order to protect the passengers or the mission. Those standards may be achieved by implementing fault-tolerant topologies. Most of these solutions propose to add new components to the system as redundant inverter legs or to increase the number of the phases of the machines, in the interest of adding more Degrees of Freedom (DoF). However, it usually increases the cost and the weight of the system as well [4][5][11]-[13]. Finally, the cost of the application is always a constraint in any industry. The new technologies and the material mutualisation reduce the application's initial cost as the reduction of the system's weight reduces the operational cost.

Under this context, this paper analyzes the behavior in degraded mode of a series-connected dual-machine drive for an aerospace application with two isolated electrical sources. Even though series connected machines are not regularly present in the industry, its functioning was already confirmed theoretically and experimentally [14]-[20]. A special electrical coupling between the machines allows their independent control. But, in the first papers, it was only possible to connect in series two machines with an odd number of phases [14]. In [17], a symmetrical 6-phase machine is connected either to a 3phase one or to an asymmetrical 6-phase machine. This paper presents a new connection of two symmetrical 6-phase machines.

The series connection mutualizes the inverter legs, thus reducing the system's weight and cost. The constraint mostly mentioned in papers [14]-[20] is the increase of the total Joule losses of the system. As a consequence, for systems whose operation of the drives is required in permanent operation, 
using series-connected machines leads to a high cost of operation. This point has to be taken into account for the drive design. However, for applications where the functioning of the drives is required for a short duration, like a Thrust Vector Control (TVC) system for example, the investment cost is highly reduced while the operation cost is neglected.

Recent studies have analyzed the series-connected topologies in degraded mode [19]-[20]. Those papers compared the same two topologies as this paper for the same aerospace application. They demonstrate by simulation that the seriesconnected dual-motor usually has lower peak currents in degraded mode in comparison with the H-bridge topology. This happens mostly because of the fact that some homopolar currents are null, thanks to the two isolated electrical sources.

This paper will continue the analysis of the seriesconnected dual-machines topology and the H-bridge topology in degraded mode, including the comparison of different control strategies that were not investigated in [19]-[20]. Both topologies are composed of two 6-phase machines, which may be represented by 4 fictitious machines according to the multiphase multi-machine theory [21]. This representation will be more detailed later in this paper. It is possible to control the real machine's torque and speed by controlling only one of these fictitious machines (the main machine). Therefore, some analysis will be carried out by comparing maximum voltage and peak current obtained with two topologies when the control strategies of the other fictitious machines (secondary and homopolar machines) are proposed. Two regular controls are considered and called "zero voltage" and "zero current" control. For each control strategy the analysis will also rely on the inverter's power sizing, which takes into account the number of transistors, the peak current and the peak voltage reference, both in degraded mode.

The paper is organized as follows. The first part introduces the aerospace application analyzed in this paper, with its specifications, and the two dual-motor fault-tolerant topologies. The reasons why these topologies are appropriate to the studied application and the conclusions of the previous analysis are also reminded in this first part of the paper. The topologies analyzed in this paper are described in the second part. A third part lists the possible different control strategies for each topology and its impact in the system performance. The last part compares the simulation and experimental results.

\section{SERIES CONNECTION TOPOLOGIES AND APPLICATION}

Different papers have already shown analytically and experimentally how two machines connected in series can be controlled independently [14][17][20]. Those topologies require a special electric connection between machines and are necessarily composed by at least one multiphase machine, in order to have enough degrees of freedom to control both machines.

The system is potentially fault-tolerant thanks to the use of multi-phase machines and the series connection of the machine inductances, reducing the peak current in degraded mode. The fault-tolerant advantages of the series connection were only highlighted in recent papers [19][20]. Therefore, the series connection topology is appropriate to a fault-tolerant dualmachine application whose global benefit consists in the weight and volume reduction.

The Thrust Vector Control (TVC) system can be considered as a good candidate for using a series-connection of machines because of the proper operating characteristics. The reason is that it is composed of two mechanical actuators responsible for controlling the rocket's trajectory. Usually, the hydraulic power system drives the actuators thanks to their high power density. However, the system is susceptible to oil leaks and the use of electric cables, instead of piping, increases the flexibility during the rocket assembly. In addition, as the duration of a space mission is relatively short, the weight reduction has more impact towards the global system efficiency than the machine's Joule losses. But in order to respect the high reliability requirements of the space industry, the drive has to be faulttolerant.

The actuators are spatially placed $90^{\circ}$ from each other around the thruster. They swivel it in comparison with the rocket axis up to a $\theta$ angle of $6^{\circ}$ in all directions $\left(\varphi\right.$ from $0^{\circ}$ to $360^{\circ}$ ) (see Fig. 1 and Fig. 2). The speed reference of each machine will depend on the two polar parameters $(\theta$ and $\varphi)$. The maximum speed will be required when $\theta$ angle is maximum, in order to obtain the maximum tilt angle as fast as possible. The $\varphi$ angle will distribute the effort between two actuators. For example, if the swiveling direction is aligned with one actuator's axis, this actuator will do all the effort. The equations 1 and 2 represent the speed reference $\left(\Omega_{i r}\right)$ for an angle $\theta$ of $6^{\circ}$ depending on the tilt angle $(\varphi)$.

$$
\begin{aligned}
& \Omega_{1 \mathrm{r}}=\Omega_{\text {MAX }} \cos (\varphi) \\
& \Omega_{2 \mathrm{r}}=\Omega_{\text {MAX }} \sin (\varphi)
\end{aligned}
$$
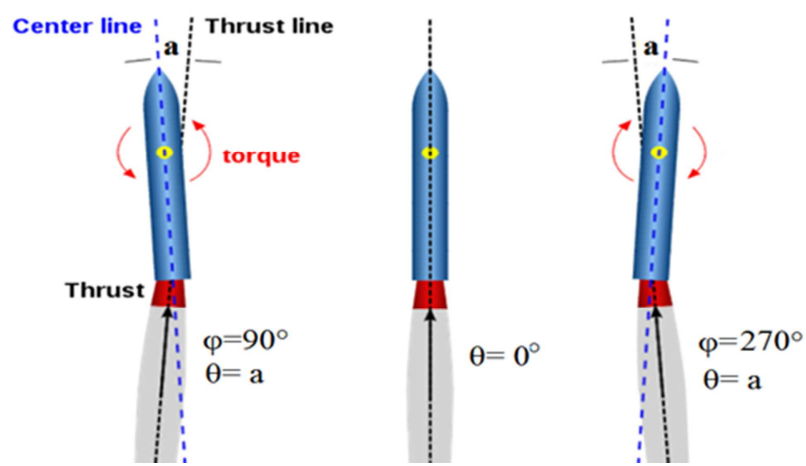

Fig. 1: Representation of the torque generation under 3 different thrust tilt angles.
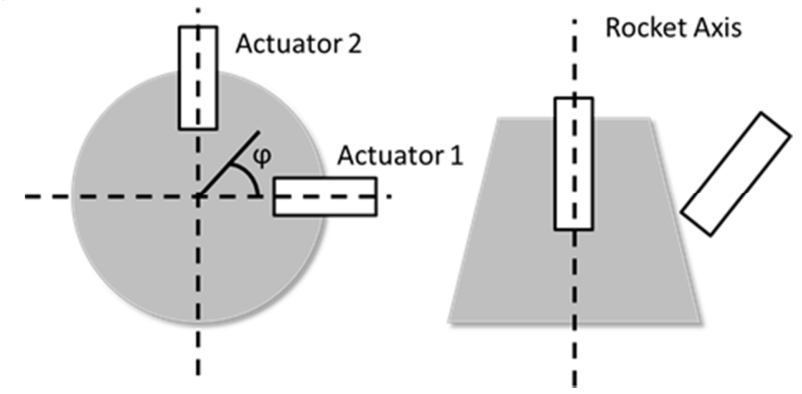

Fig. 2: Up (left) and side (right) views of the thruster (grey) and the two mechanical actuators (white rectangles). 


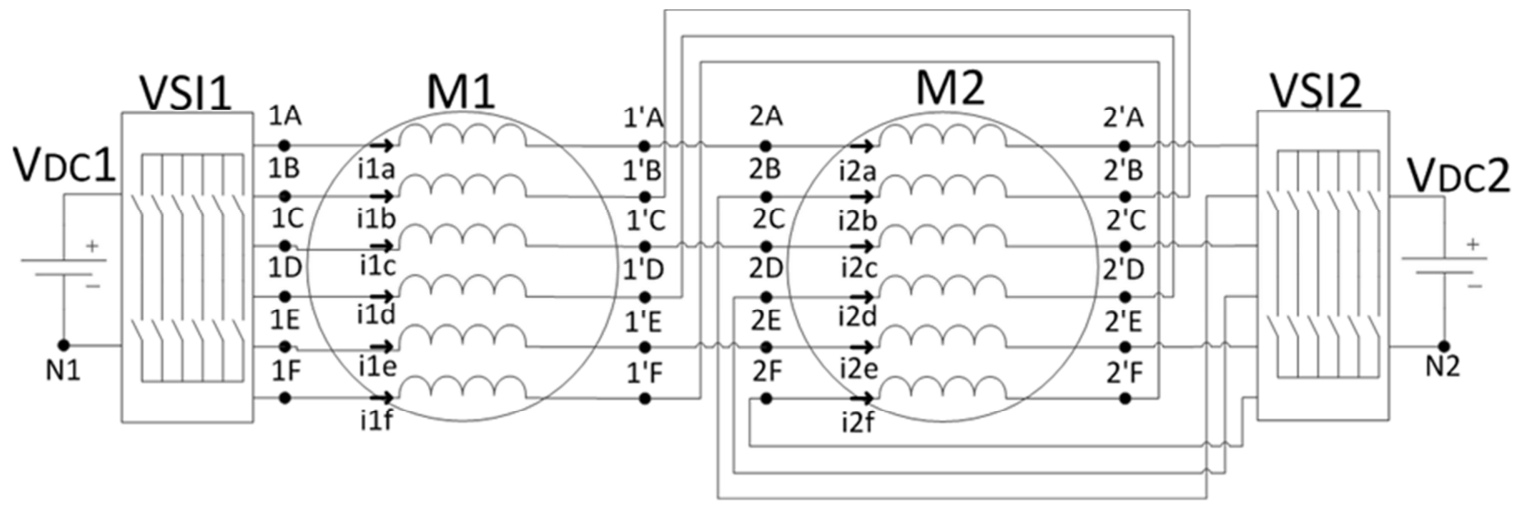

Fig. 3: RIMM Topology.

\section{FAULT-TOLERANT TOPOLOGIES}

The drive specified in the studied aerospace application is the RIMM (Redundant Inverter Multiple Machine) topology (Fig. 3). It is composed of two 6-phase open-end winding PMSMs. Two machines control two electro-mechanical actuators. The number of phases was defined in order to respect the maximum value of voltage of the electric sources and to reduce the current per phase, most importantly in degraded mode. The open-end winding machines have a good performance in degraded mode, because it reduces the impact of the fault on the healthy phases, especially if it is an opened circuit fault [12]. The permanent magnets raise the power density of the machines. The topology is supplied by two isolated electrical sources, increasing the system functional reliability and nullifying the homopolar current which is normally created by $6 * k$ harmonics.

Previous studies [19][20] have compared the RIMM topology to a standard H-bridge topology (Fig. 4), in which the two 6-phase PMSM are independently supplied by 24 inverter legs (two legs for one machine phase) with only one DC-bus at the same voltage level as the RIMM topology, $\mathrm{V}_{\mathrm{DC}}=\mathrm{V}_{\mathrm{DC} 1}=\mathrm{V}_{\mathrm{DC} 2}$. Besides the fact that RIMM topology needs only half as many transistors as the H-bridge topology, simulation results have shown that their current dimensioning is lower, taking into account the peak current in degraded mode (Fig. 5). These results confirm the advantages of the series connection topology for the analyzed application. The speed references $\Omega_{r e f-1}$ and $\Omega_{r e f-2}$ are mentioned in [20], which correspond to the worst cases for the studied application.

\section{PROPOSED CONTROL STRATEGIES}

As both topologies are composed of multiphase machines, the control is developed by decomposing the real machines in fictitious electrically decoupled diphase and homopolar machines [20]. The equations from 3 to 6 represent the voltage $\mathrm{V}$ equations of each fictitious machine of a 6-phase symmetrical machine according to the machine parameters: resistance $\mathrm{R}$, inductances $\mathrm{L}$ and back-electromotive forces (back-EMF) E. The index "m", "s", "h1" and "h2" represent respectively the diphase main and secondary machines and the one-dimensional homopolar machines 1 and 2. Each of them interacts with some ranks of harmonics (Table I), for example the main machine interacts with the fundamental current and Back-EMF. The machine's torque is equal to the sum of each fictitious machine's torque.

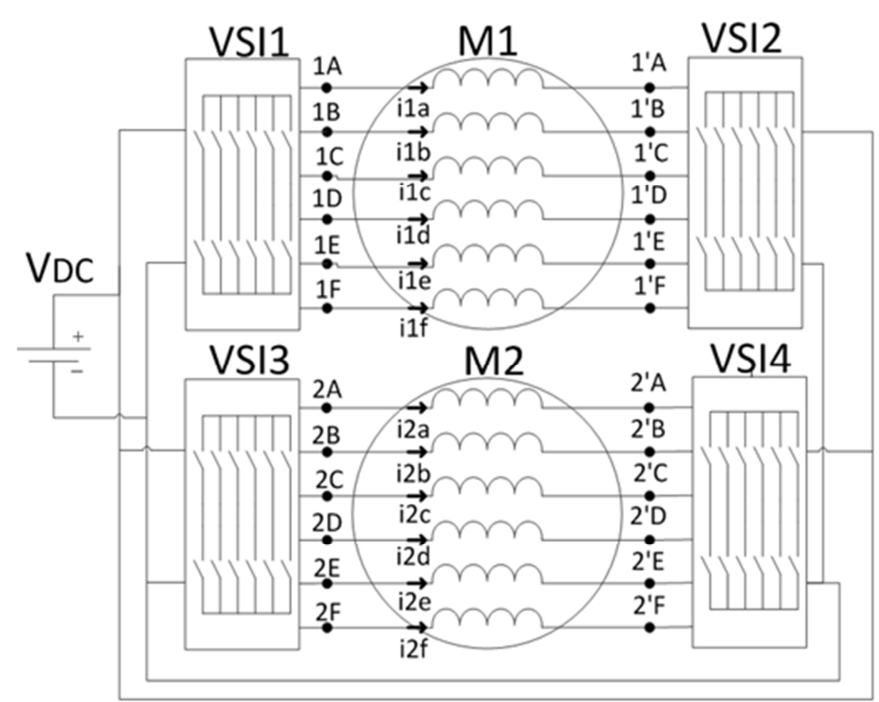

Fig. 4: H-bridges topology.

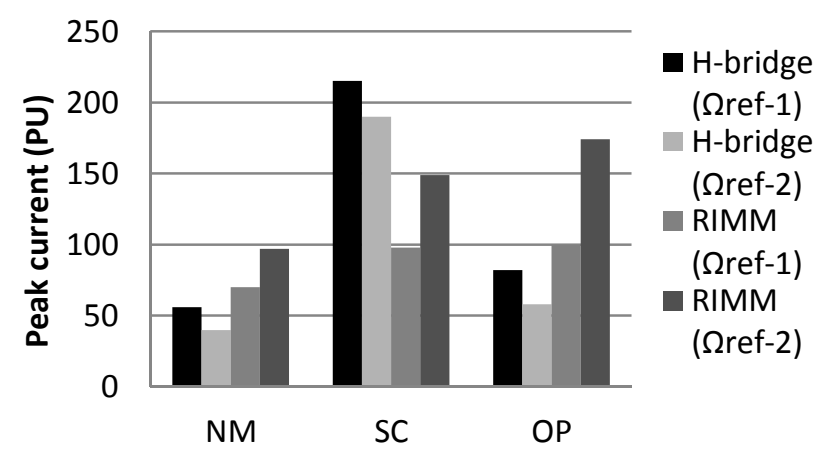

Fig. 5: Peak current in normal mode (NM) and in degraded mode (Transistor Short-Circuit (SC) and Opened Phase (OP)). 


$$
\begin{gathered}
{\left[\mathrm{V}_{\mathrm{m}}\right]=\mathrm{R}\left[\mathrm{I}_{\mathrm{m}}\right]+\left[\mathrm{L}_{\mathrm{m}}\right] \frac{d\left[I_{m}\right]}{d t}+\left[E_{m}\right]} \\
{\left[\mathrm{V}_{\mathrm{s}}\right]=\mathrm{R}\left[\mathrm{I}_{\mathrm{s}}\right]+\left[\mathrm{L}_{\mathrm{s}}\right] \frac{d\left[I_{s}\right]}{d t}+\left[E_{s}\right]} \\
V_{h 1}=R I_{h 1}+L_{h 1} \frac{d I_{h 1}}{d t}+E_{h 1} \\
V_{h 2}=R I_{h 2}+L_{h 2} \frac{d I_{h 2}}{d t}+E_{h 2}
\end{gathered}
$$

TABLE I: HARMONIC DISTRIBUTION OF THE FICTITIOUS MACHINES

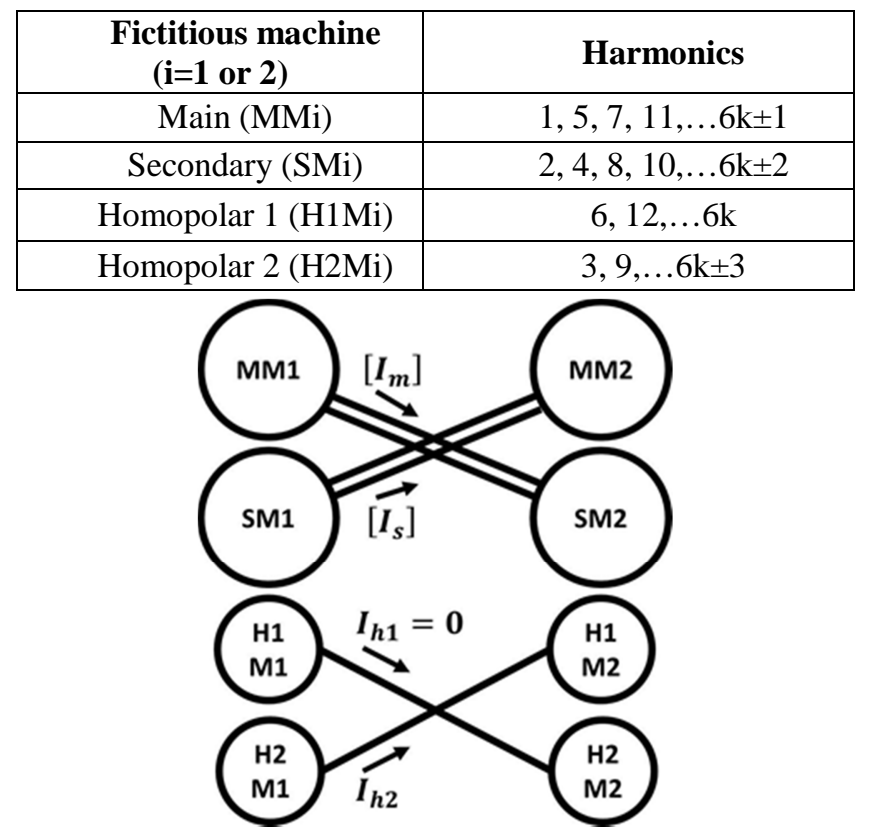

Fig. 6: Scheme of the RIMM topology's fictitious machine series connection.

As demonstrated analytically in previous papers [19][20] and in the appendix of this paper, the fictitious machines of the RIMM topology are also coupled in series as the diagram below (Fig. 6), sharing the same currents. It is important to emphasize that the current $I_{h 1}$ of the RIMM topology is null because of the two isolated electrical sources.

In a regular machine control, only the main-machine currents are regulated in order to control the machine torque or speed. In healthy operating mode, the currents of the other fictitious machines depend only on the related Back-EMF harmonics (if they exist) since the voltage references are null (see equations (4) to (6)). If the Back-EMF is sinusoidal, in healthy mode, all voltages and currents of fictitious machines are equal to zero.

In degraded mode, voltages and currents of the 6-phase machine become unbalanced, leading to a coupling between the fictitious machines, increasing the current amplitudes. On the equation (7), the coupling factor $\left(f_{\mathrm{COUPx}}\right)$ is difficult to demonstrate analytically because it depends on the current of the others fictitious machines and the system is unbalanced.

$$
\left[\mathrm{V}_{\mathrm{x}}\right]=\mathrm{R}\left[\mathrm{I}_{\mathrm{x}}\right]+\left[\mathrm{L}_{\mathrm{x}}\right] \frac{d\left[I_{x}\right]}{d t}+\left[E_{x}\right]+f_{\operatorname{COUPX}}
$$

The "zero voltage" strategy $\left(\left[V_{x}\right]=0\right)$, the most regular one for the non-main machines, is represented by the equation (8), in which the currents of the fictitious machine depend on the coupling factor and the Back-EMF. Looking forward to nullify the current of some fictitious machines, the "zero current" control strategy $\left(\left[I_{x}\right]=0\right)$ may be implemented. In that case, the voltage of the fictitious machine will depend on the coupling factor and the Back-EMF, as shown by equation (9). The "zero current" control strategy may be interesting when the machines parameters may lead to an amplification of the current amplitude and oscillation in degraded mode.

$$
\begin{gathered}
I F\left[V_{x}\right]=0 \rightarrow \mathrm{R}\left[\mathrm{I}_{\mathrm{x}}\right]+\left[\mathrm{L}_{\mathrm{x}}\right] \frac{d\left[I_{x}\right]}{d t}=-\left[E_{x}\right]-f_{\text {COUP } x} \\
I F\left[I_{x}\right]=0 \rightarrow\left[\mathrm{V}_{\mathrm{x}}\right]=\left[E_{x}\right]+f_{\text {COUPX }}
\end{gathered}
$$

Figures 7 and 8 show the currents of the fictitious machine that might be regulated depending on the chosen control strategy (TABLE II). The matrixes $\left[C_{6}\right]$ and $\left[P_{6}\right]$ are respectively the Concordia and Park transformation for a symmetrical 6-phase machine.

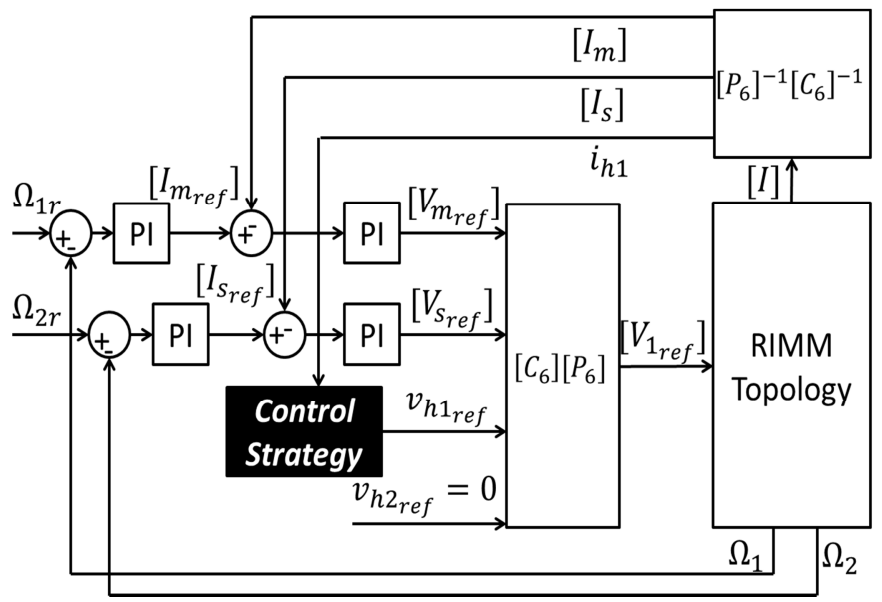

Fig. 7: Control diagram of RIMM topology.

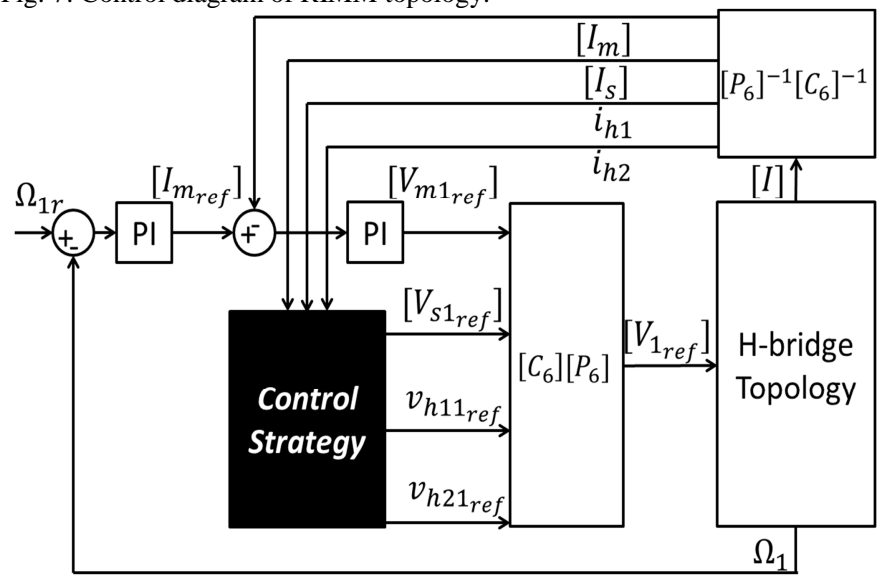

Fig. 8: Control diagram of one machine in H-bridge topology.

\begin{tabular}{|c|c|}
\hline \multicolumn{2}{|c|}{ TABLE II: Control strategies } \\
\hline $\begin{array}{c}\text { Control Strategy } \\
\text { "zero voltage" } \\
V=0\end{array}$ & Voltage Reference \\
\hline & $v_{\text {ref }}=0$ \\
"zero current" & $i_{\text {ref }}=0$ \\
$I=0$ & $\rightarrow$ \\
\hline
\end{tabular}


Even though, in H-bridge topology, each machine has its own control chain, the control strategy of the machines will not differ from each other. For the H-bridge topology, all the nonmain machines (secondary and two homopolar machines) are controlled by imposing a zero current or a zero voltage. However, for the RIMM topology, the two control strategies can only be implemented to one homopolar machine (related to the $3^{\text {rd }}$ harmonics of electrical variables). One of the homopolar machines' currents is always null, thanks to the two isolated electrical sources. Then the secondary machine of M1 (SM1) is coupled with the main machine of M2 (MM2) and vice-versa.

Under these circumstances, it is possible to list the control strategies taken into account in this paper for RIMM topology:

- $\quad V_{h 2}$ null, defined as 0

- $\quad I_{h 2}$ null, defined as 1

And for H-bridge topology, there are more possibilities $\left(2^{3}\right.$ $=8$ ), because of the combinations of "zero voltage" and "zero current" control strategies for the three non-main fictitious machines:

- $\quad\left[V_{s}\right], V_{h 1}$ and $V_{h 2}$ null, defined as 000;

- $\quad\left[V_{s}\right], V_{h 1}$ and $I_{h 2}$ null, defined as 001;

- $\quad\left[V_{S}\right], I_{h 1}$ and $V_{h 2}$ null, defined as 010;

- $\quad\left[V_{s}\right], I_{h 1}$ and $I_{h 2}$ null, defined as 011;

- $\quad\left[I_{S}\right], V_{h 1}$ and $V_{h 2}$ null, defined as 100 ;

- $\quad\left[I_{s}\right], V_{h 1}$ and $I_{h 2}$ null, defined as 101;

- $\quad\left[I_{s}\right], I_{h 1}$ and $V_{h 2}$ null, defined as 110 ;

- $\quad\left[I_{s}\right], I_{h 1}$ and $I_{h 2}$ null, defined as 111 ;

\section{SIMULATION AND EXPERIMENTAL RESULTS}

\section{A. Test conditions}

All the tests take into account the worst conditions for each topology obtained during the previous studies [19][20].

H-bridge $\rightarrow 1$ machine at $50 \mathrm{rad} / \mathrm{s}\left(\Omega_{1 \mathrm{r}}=50 \mathrm{rad} / \mathrm{s}\right)$ and the other stopped;

RIMM $\rightarrow 2$ machines at $35.35 \mathrm{rad} / \mathrm{s}\left(\Omega_{1 \mathrm{r}}=\Omega_{2 \mathrm{r}}=\right.$ $35.35 \mathrm{rad} / \mathrm{s})$;

These two speed references represent the maximum swiveling in the axis of one actuator $\left(\varphi=0^{\circ}\right.$ or $\left.90^{\circ}\right)$ and in the axis that is exactly in the middle of the two actuators $\left(\varphi=45^{\circ}\right)$ respectively. These speeds were obtained with equations 1 and 2.

Two degraded modes will be analyzed:

- One transistor short-circuited (SC);

- $\quad$ One opened phase (OP);

Both faults are among the most common ones in inverters [1][10].

\section{B. Simulation Results and Analysis}

The graphics on figures 9 to 12 present the peak current and demanded peak-voltage on degraded mode for different control strategies for both topologies.

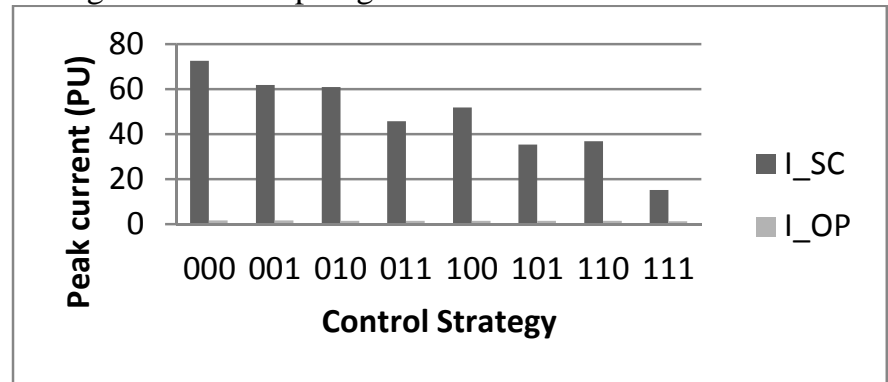

Fig. 9: (Simulation) H-bridge's peak current in degraded modes for different control strategies.

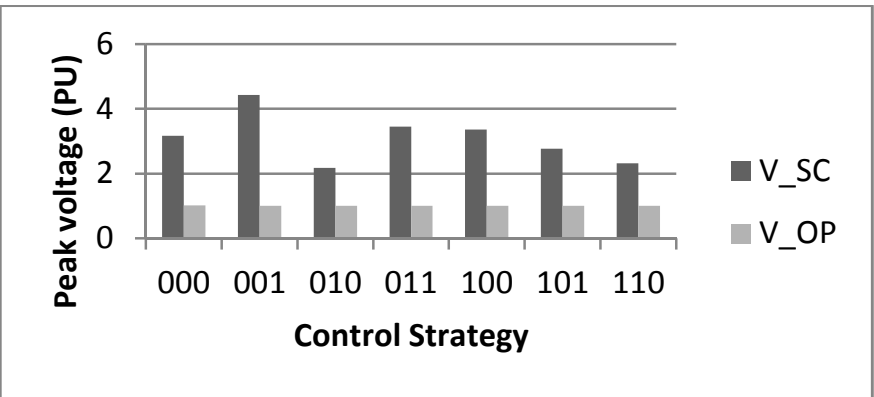

Fig. 10: (Simulation) H-bridge's demanded peak voltage in degraded modes for different control strategies.

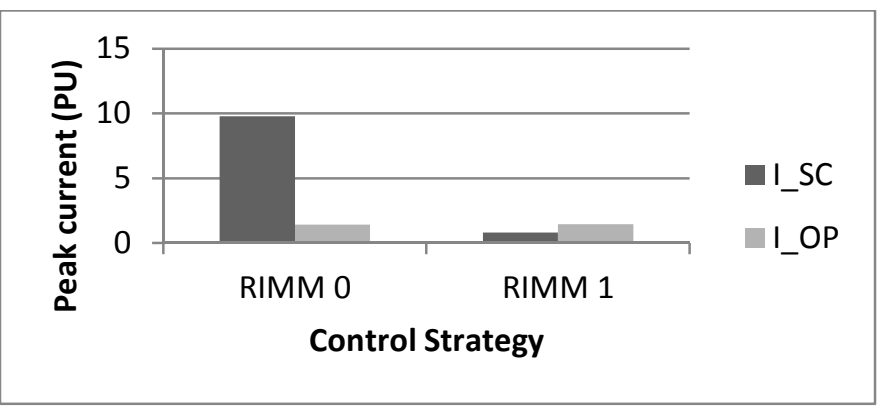

Fig. 11: (Simulation) RIMM's peak current in degraded modes for different control strategies.

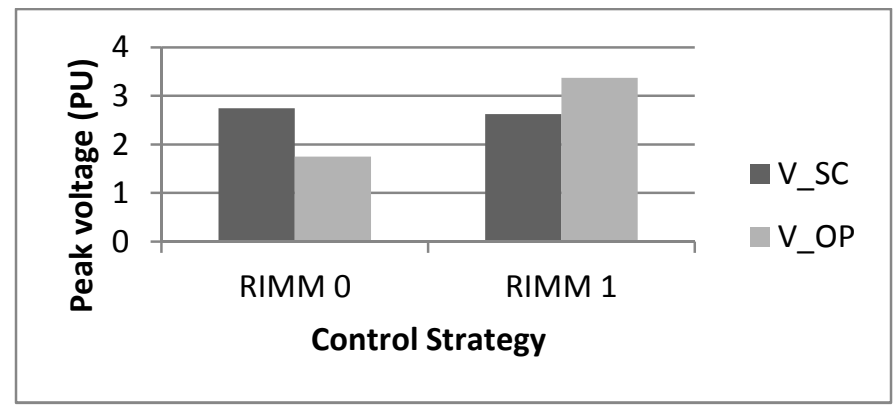

Fig. 12: (Simulation) RIMM's demanded peak voltage in degraded mode for different control strategies.

It is possible, by analyzing these four graphics, to highlight some relations between both topologies performance on 
degraded mode and the control strategy. The control strategies impact significantly on both peak current and peak voltage during a short-circuited transistor fault. The same is not true for the opened phase fault. This happens because the current on the non-main machines are much higher during a short-circuit fault, as shown in Fig. 9 and 11, especially for the H-bridge topology.

As expected, the control of a fictitious machine with zero current decreases the peak current in degraded modes. Otherwise, it is not possible to define a direct link between the required peak voltage and the control strategy.

For H-bridge topology, it was not possible to calculate the peak voltage and peak current for the strategy where $\left[I_{s}\right], I_{h 1}$ and $I_{h 2}$ are controlled to be null (111), because the current controllers saturated in degraded mode. In fact, it is not possible to impose zero currents for all the secondary and homopolar machines in degraded mode, because of the loss of one DoF. Otherwise, the current magnitude can be lower in the case for the RIMM topology thanks to the series connection of the machines inductance.

\section{Experimental Results and Analysis}

A test bench built for this experiment is reported in Fig. 13. It is composed of two identical 6-phase PMSM, two 6-leg inverters, two isolated DC-sources, two industrial drives to simulate the load for the studied PMSMs, a MicroLabBox from dSPACE and one current measurement box.

As the bench has only 12 inverter legs, all the tests for the $\mathrm{H}$-Bridge have been carried out for only one machine. This is not a constraint considering that both machines are independently supplied and the only difference would be the DC-source losses, which is considered as negligible for both simulation and experimental results.

Figures 14 to 18 show some results obtained with the test bench for both analyzed topologies. Figures 19 to 21 compare the experimental results to the simulation ones in order to verify the relation between the topology behavior in degraded mode and the control strategy. The inverter's dimensioning power can be obtained by the product of the demanded peakvoltage, peak current and the number of transistors. The dimensioning power is an image of the cost and the volume of the inverter. The variable's values on normal mode were used to calculate the per unit values presented on the graphics.

Because of the high amplitude of the currents of the $\mathrm{H}$ bridge topology during a short-circuit fault, it was not possible to reproduce the same test experimentally. During the shortcircuit fault, the current in the degraded phase becomes unidirectional, which means that $I_{h 1}$ and $I_{h 2}$ has a continuous component, only limited by the resistance of the degraded phase. In RIMM topology, the structure itself cancels the $I_{h 1}$ current and the phase resistance is twice as high thanks to the machines' series connection. Despite the fact that the RIMM currents during a short circuit fault are also unidirectional, their amplitude is much lower. Consequently, for the test bench described in this paper, the H-bridge topology cannot tolerate a short-circuit fault, but the RIMM topology can.

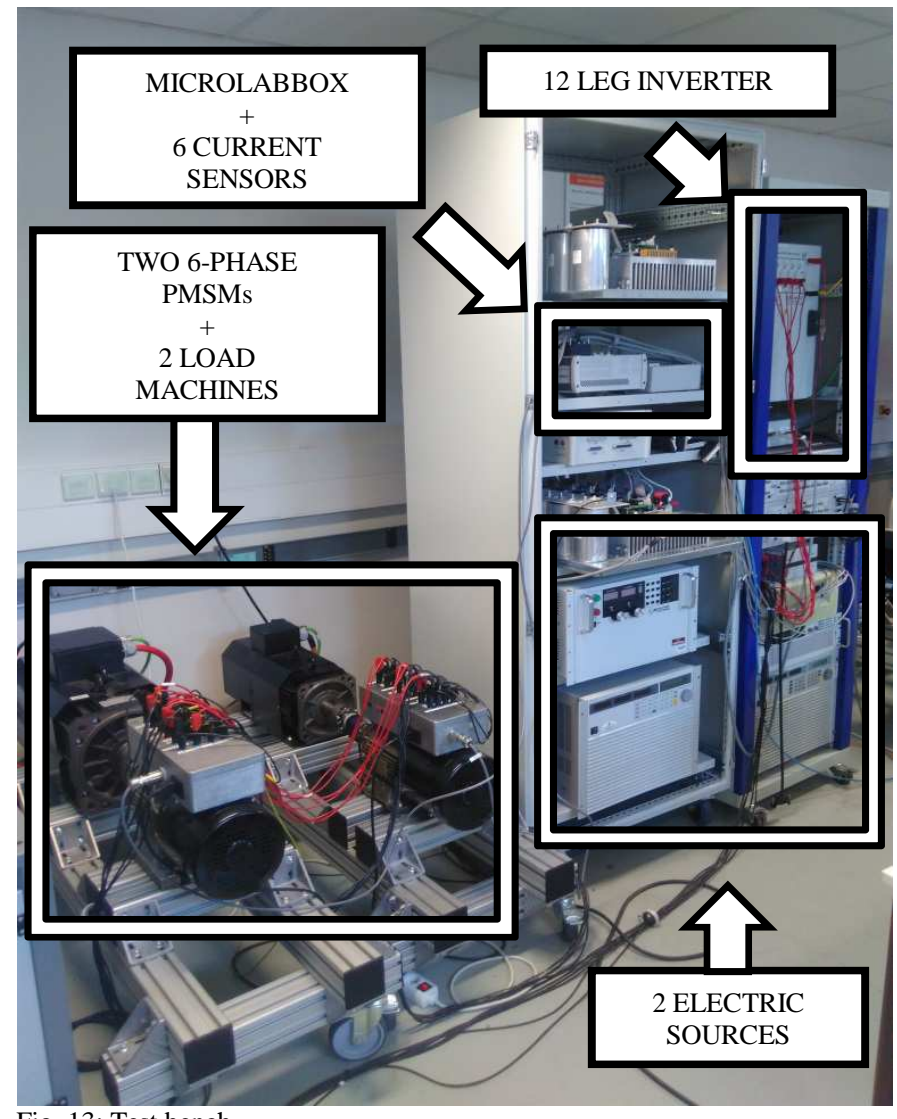

Fig. 13: Test bench.

In figures 14 and 15 , it is possible to see an impact of the strategy control on the current curve forms but much less on the amplitude. Figure 18 shows that this happens for all control strategies as expected after the simulation results. Otherwise, the comparison of figures 16 and 17 shows that the DC constant component on the currents is eliminated by changing the control strategy, reducing consequently the current amplitude. This behavior also validates the simulation results (Fig. 20). The fault tolerant capability is assured by figure 18, which shows that the speed is constant in degraded mode.

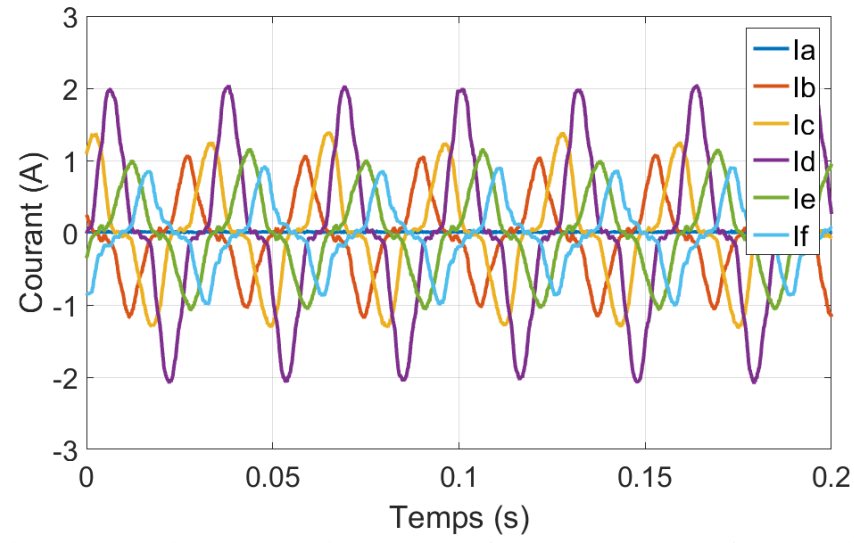

Fig. 14: (Experimental) H-bridge currents for an opened phase fault and the 000 strategy control. 


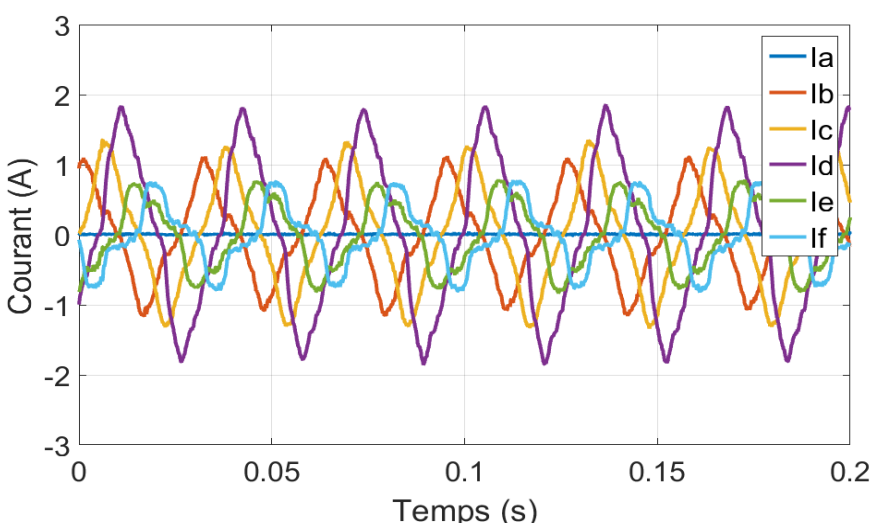

Fig. 15: (Experimental) H-bridge currents for an opened phase fault and the 101 strategy control.

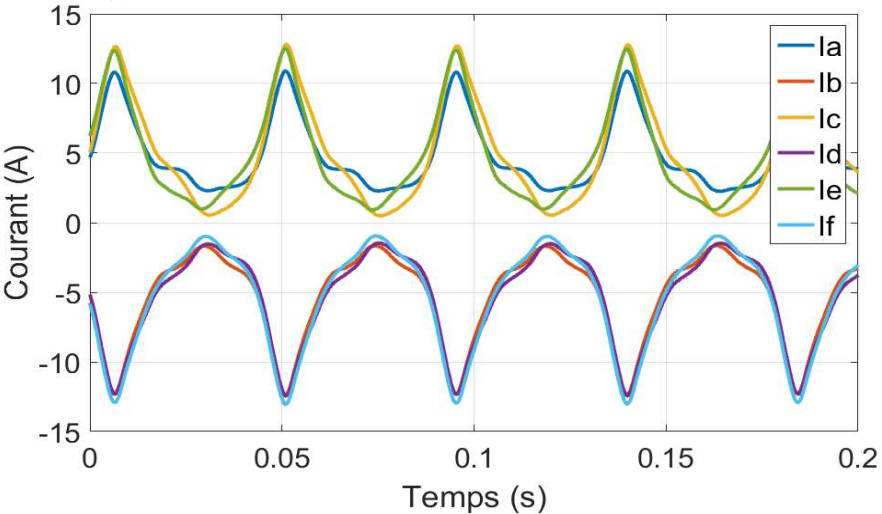

Fig. 16: (Experimental) RIMM currents for a short-circuit fault and $V_{h 2}=0$.

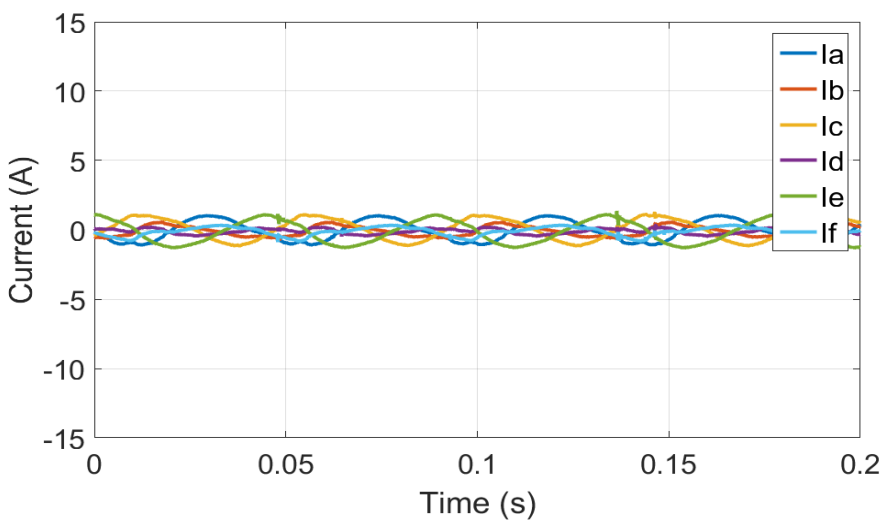

Fig. 17: (Experimental) RIMM currents for a short-circuit fault and $I_{h 2}=0$.

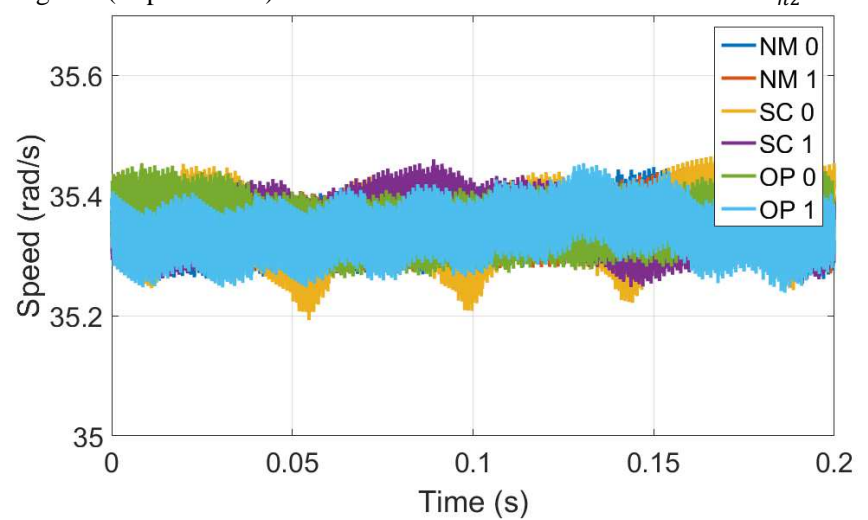

Fig. 18: (Experimental) RIMM's measured speed for different control strategies in normal mode (NM) and degraded modes (SC and OP).

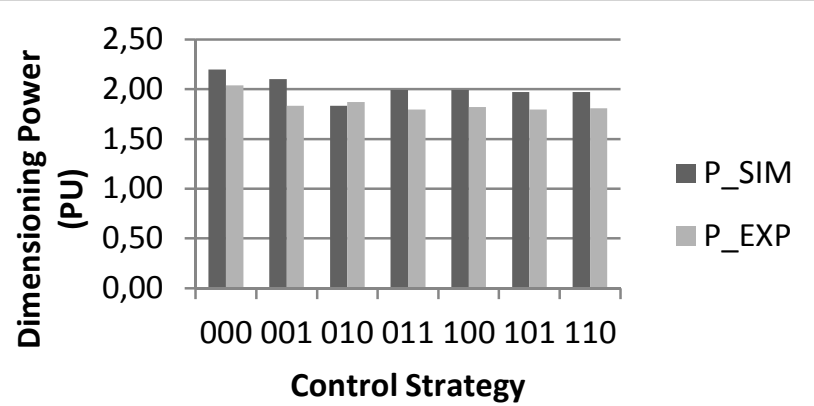

Fig. 19: H-bridge's dimmensioning power in degraded mode for different control strategies in simulation and experimentally.

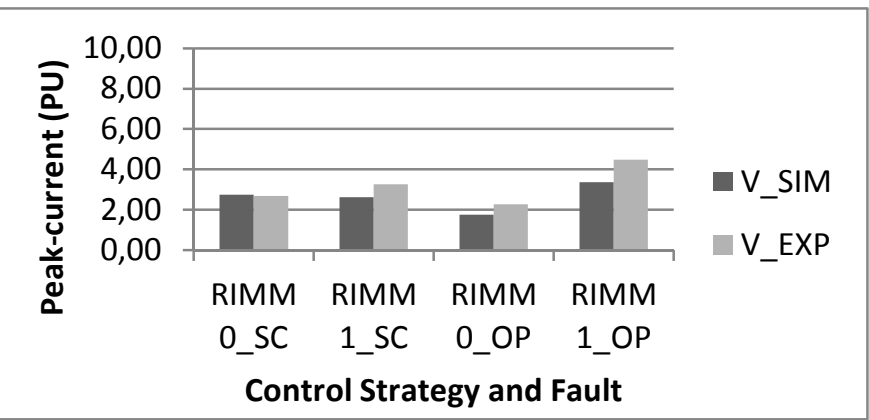

Fig. 20: RIMM's peak current in degraded mode for different control strategies in simulation and experimentally.

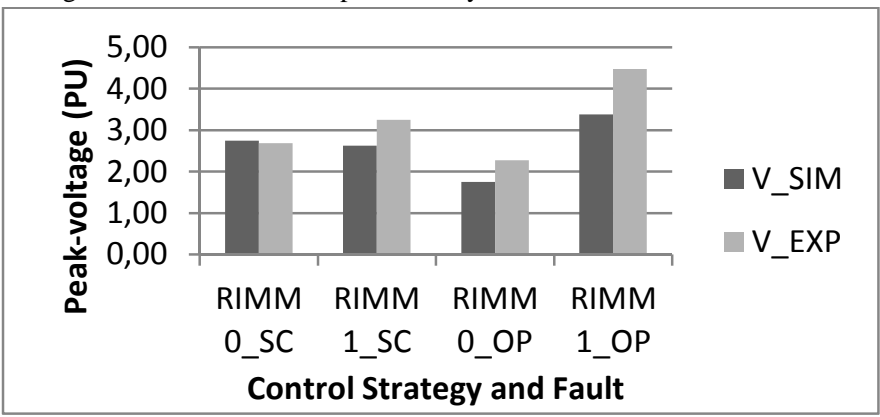

Fig. 21: RIMM's demanded peak voltage in degraded mode for different control strategies in simulation and experimentally.

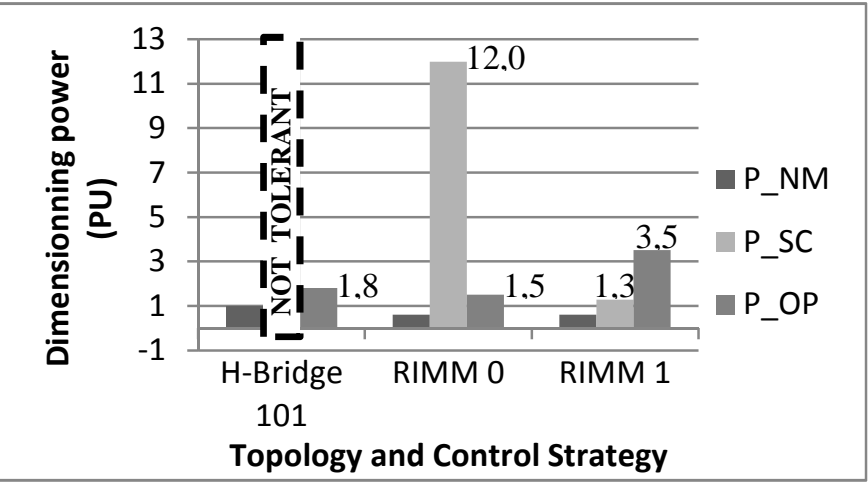

Fig. 22: (Experimental) Power dimensioning for H-bridge 101 and two control strategies of RIMM topology: RIMM 0 for "zero voltage" and RIMM 1 for "zero current".

Mostly, the experimental results (EXP) confirm the behavior expected during simulation results (SIM) analysis, especially for the peak current and dimensioning power of the transistors (Fig. 19 to 21). When controlling a RIMM topology 
with $i_{h 2}=0$ strategy, there is a significant difference between the results on simulation and experimentally obtained, specially analyzing the peak voltage (Fig. 21). In this case, the controllers are slightly saturated, and its impact is more experimentally prominent.

Finally, Figure 22 presents the dimensioning power of both topologies, taking into account both control strategies for the RIMM topology: "zero voltage" (RIMM 0) and "zero current" (RIMM 1). If the system has to be tolerant to both faults analyzed in this paper, H-bridge topology is not an option and the dimensioning power of RIMM 1 is 3,4 times lower than the one of RIMM 0 , the comparison is done taking into account the worst case for control strategy. Otherwise, if only the faulttolerance to an opened phase is compulsory, than RIMM 0 has the lowest dimensioning power, $17 \%$ lower than the H-Bridge topology and 57\% lower than RIMM 1.

\section{CONCLUSION}

This paper has analyzed the impact of the control strategy of the dual-multiphase machines on the topology performance and inverter dimensioning on degraded mode. The experimental results have confirmed the theory and the simulation results concerning the comparison of the different control strategies and also the comparison of both topologies.

The control strategy that is the most appropriate for the RIMM topology depends on the industrial requirements and priorities of the application. The implementation of a "zero voltage" strategy reduces the power dimensioning if only an opened phase fault is taken into account. If the tolerance of a short-circuited transistor is compulsory, the "zero current" control strategy is more convenient, because of its low peak currents.

\section{REFERENCES}

[1] A. Garcia, J. Cusido, J. A. Rosero, J. A. Ortega, and L. Romeral, "Reliable electro-mechanical actuators in aircraft," IEEE Aerospace and Electronic Systems Magazine, vol. 23, no. 8, pp. 19-25, Aug. 2008.

[2] A. Boglietti, A. Cavagnino, A. Tenconi, S. Vaschetto, and P. di Torino, "The safety critical electric machines and drives in the more electric aircraft: A survey," presented at the IECON'09, 2009, pp. 2587-2594.

[3] W. Cao, B. C. Mecrow, G. J. Atkinson, J. W. Bennett, and D. J. Atkinson, "Overview of Electric Motor Technologies Used for More Electric Aircraft (MEA)," IEEE Trans. Ind. Electron., vol. 59, no. 9, pp. 3523-3531, Sept. 2012.

[4] J. Bennett, G. Atkinson, B. Mecrow and D. Atkinson "Fault tolerant design considerations and control strategies for aerospace drives", IEEE Trans. Ind. Electron., vol. 59, no. 5, pp.2049 -2058, May 2012.

[5] M. Villani , M. Tursini , G. Fabri and L. Castellini "High reliability permanent magnet brushless motor drive for aircraft application", IEEE Trans. Ind. Electron., vol. 59, no. 5, pp.2073 -2081, May 2012.

[6] M. Jones, S. N. Vukosavic, and E. Levi, "Parallel-Connected Multiphase Multidrive Systems With Single Inverter Supply," IEEE Trans. Ind. Electron., vol. 56, no. 6, pp. 2047-2057, Jun. 2009.

[7] D. Dujic, M. Jones, S. N. Vukosavic, and E. Levi, "A General PWM Method for a $(2 \mathrm{n}+1)$-Leg Inverter Supplying $\mathrm{n}$ Three-Phase Machines," IEEE Trans. Ind. Electron., vol. 56, no. 10, pp. 4107-4118, Oct. 2009.

[8] T. Bensalah, M. Py, and P. Thalin, "PRISCA Modular Electrical Power Management," presented at the MEA 2012 More Electric Aircraft, Bordeaux, France, 20-21 Nov. 2012.
[9] T. Tanaka, A. Hara, M. Iwashita, and K. Matsuse, "Characteristics of independent vector control of two induction motors fed by a five-leg inverter with space vector modulation," presented at the IPEMC, 2012, vol. 4, pp. 2431-2438.

[10] W. Wang, M. Cheng, B. Zhang, Y. Zhu, and S. Ding, "A Fault-Tolerant Permanent-Magnet Traction Module for Subway Applications," IEEE Trans. Power Electron., vol. 29, no. 4, pp. 1646-1658, Apr. 2014.

[11] L. de Lillo, L. Empringham, P. Wheeler, S. Khwan-On , C. Gerada, M. Othman and X. Huang "Multiphase power converter drive for faulttolerant machine development in aerospace applications", IEEE Trans. Ind. Electron., vol. 57, no. 2, pp.575 -583, Feb. 2010.

[12] B. A. Welchko, T. A. Lipo, T. M. Jahns, and S. E. Schulz, "Fault tolerant three-phase AC motor drive topologies: A comparison of features, costs, and limitations," IEEE Trans. Power Electron., vol. 19, no. 4, pp. 1108-1116, Jul. 2004.

[13] R. R. Errabelli and P. Mutschler, "Fault-Tolerant Voltage Source Inverter for Permanent Magnet Drives," IEEE Trans. Power Electron., vol. 27, no. 2, pp. 500-508, Feb. 2012.

[14] E. Levi, M. Jones, S.N. Vukosavic, H.A. Toliyat, "A Novel Concept of a Multiphase, Multimotor Vector Controlled Drive System Supplied From a Single Voltage Source Inverter", IEEE Trans. Power Electron., vol. 19, no. 2, pp. 320-335, March 2004.

[15] E. Semail, E. Levi, A. Bouscayrol, and X. Kestelyn, "Multi-machine modelling of two series connected 5 phase synchronous machines: effect of harmonics on control," Power Electronics and Applications, 2005 European Conference, Dresden (Germany), Sept. 2005, pp. 1-10.

[16] A. Iqbal , S. Vukosavic , E. Levi , M. Jones and H. A. Toliyat "Dynamics of a series-connected two-motor five-phase drive system with a single-inverter supply", Conf. Rec. IEEE IAS Annu. Meeting, 2005,pp.1081-1088.

[17] D. Dujic, M. Jones, E. Levi, and O. Lopez, "DC-bus utilisation in seriesconnected multi-phase machines supplied from a VSI with a composite phase number," Electrical Machines (ICEM), 2010 XIX International Conference, Rome, 2010, pp. 1-6.

[18] F. Mekri, J.-F. Charpentier, and E. Semail, "An efficient control of a series connected two-synchronous motor 5-phase with non sinusoidal EMF supplied by a single 5-leg VSI: Experimental and theoretical investigations," Electric Power System Research, vol. 92, pp 11-19, Nov. 2012.

[19] T. J. dos Santos Moraes, N. K. Nguyen, F. Meinguet, and E. Semail, "Fault Tolerant Dual-Motor Drives: Sizing of Power Electronic," presented at the EPE'15 ECCE Europe, 2015, pp. 1-10.

[20] T. J. dos Santos Moraes, N. K. Nguyen, F. Meinguet, and E. Semail, "A Comparative Study of Two Fault-Tolerant DualMotor Drive Topologies Under Short-Circuit Inverter Switch Fault," presented at the ISIE 2015, 2015, pp. 1574-1579.

[21] E. Semail, A. Bouscayrol, J.-P. Hautier, "Vectorial formalism for analysis and design of polyphase synchronous machines," European Physical Journal: Applied Physics, EDP Sciences, Vol. 22, n0. 3, pp.207-220, May 2003.

\section{APPENDIX:}

\section{A. RIMM MODEL}

The special coupling between the two machines can express the relation between the currents of both machines by the equations below:

$$
\left.\begin{array}{c}
{\left[I_{2}\right]=[K]\left[I_{1}\right]} \\
i_{2 a} \\
i_{2 b} \\
i_{2 c} \\
i_{2 d} \\
i_{2 e} \\
i_{2 f}
\end{array}\right]=\left[\begin{array}{cccccc}
1 & 0 & 0 & 0 & 0 & 0 \\
0 & -1 & 0 & 0 & 0 & 0 \\
0 & 0 & 1 & 0 & 0 & 0 \\
0 & 0 & 0 & -1 & 0 & 0 \\
0 & 0 & 0 & 0 & 1 & 0 \\
0 & 0 & 0 & 0 & 0 & -1
\end{array}\right]\left[\begin{array}{c}
i_{1 a} \\
i_{1 b} \\
i_{1 c} \\
i_{1 d} \\
i_{1 e} \\
i_{1 f}
\end{array}\right]
$$




$$
\begin{gathered}
{[\mathrm{V}]=\left[\mathrm{V}_{1}\right]+[\mathrm{C}]\left[\mathrm{V}_{2}\right]} \\
{[K]\left[\mathrm{V}_{\alpha \beta}\right]=[K]\left[\mathrm{V}_{\alpha \beta 1}\right]+[\mathrm{C}][\mathrm{K}]\left[\mathrm{V}_{\alpha \beta 2}\right]} \\
{\left[\begin{array}{l}
v_{\alpha m} \\
v_{\beta m} \\
v_{\alpha s} \\
v_{\beta s} \\
v_{h 1} \\
v_{h 2}
\end{array}\right]=\left[\begin{array}{l}
v_{\alpha m 1} \\
v_{\beta m 1} \\
v_{\alpha s 1} \\
v_{\beta s 1} \\
v_{h 11} \\
v_{h 21}
\end{array}\right]+\left[\begin{array}{cccccc}
0 & 0 & 1 & 0 & 0 & 0 \\
0 & 0 & 0 & 1 & 0 & 0 \\
1 & 0 & 0 & 0 & 0 & 0 \\
0 & -1 & 0 & 0 & 0 & 0 \\
0 & 0 & 0 & 0 & 0 & 1 \\
0 & 0 & 0 & 0 & 1 & 0
\end{array}\right]\left[\begin{array}{c}
v_{\alpha m 2} \\
v_{\beta m 2} \\
v_{\alpha s 2} \\
v_{\beta s 2} \\
v_{h 12} \\
v_{h 22}
\end{array}\right]}
\end{gathered}
$$

In order to explain how the machines can share the same current turning in different speeds and generating different torques, the two multiphase machines will be decomposed in fictitious machines.

$$
\begin{gathered}
{\left[I_{1_{\alpha \beta}}\right]=\left[C_{6}\right][K]^{-1}\left[C_{6}\right]^{T}\left[I_{2 \alpha \beta}\right]} \\
{\left[\begin{array}{l}
i_{m \alpha 1} \\
i_{m \beta 1} \\
i_{s \alpha 1} \\
i_{s \beta 1} \\
i_{h 11} \\
i_{h 21}
\end{array}\right]=\left[\begin{array}{c}
i_{s \alpha 2} \\
-i_{s \beta 2} \\
i_{m \alpha 2} \\
-i_{m \beta 2} \\
i_{h 12} \\
-i_{h 22}
\end{array}\right]} \\
{\left[\begin{array}{l}
i_{m \alpha 1} \\
i_{m \beta 1}
\end{array}\right]=\left[\begin{array}{c}
i_{s \alpha 2} \\
-i_{s \beta 2}
\end{array}\right] \rightarrow\left[I_{m 1}\right]=\left[I_{s 2}\right]^{*}} \\
{\left[\begin{array}{l}
i_{s \alpha 1} \\
i_{s \beta 1}
\end{array}\right]=\left[\begin{array}{c}
i_{m \alpha 2} \\
-i_{m \beta 2}
\end{array}\right] \rightarrow\left[I_{s 1}\right]=\left[I_{m 2}\right]^{*}}
\end{gathered}
$$

As the equations show, the main machine of each machine is only connected to the secondary machine of the other one. This means that the currents driving the main fictitious machine of machine 1 will also drive the secondary fictitious machine of machine 2. But for a standard 6-phase symmetrical machine, the secondary machine does not generate any torque. This fictitious machine only interacts with even harmonics of the Back-EMF that are null for a standard machine, because of the rotor symmetry.

The independent control of the machines is assured because the main machines are decoupled. So the command will control the current of each main machine independently. 